\title{
Extrahepatic pseudocyst in an adult
}

\author{
Yi-An Chen, MD, Cheng-Ta Hsieh, MD, Jui-Ming Sun, MD.
}

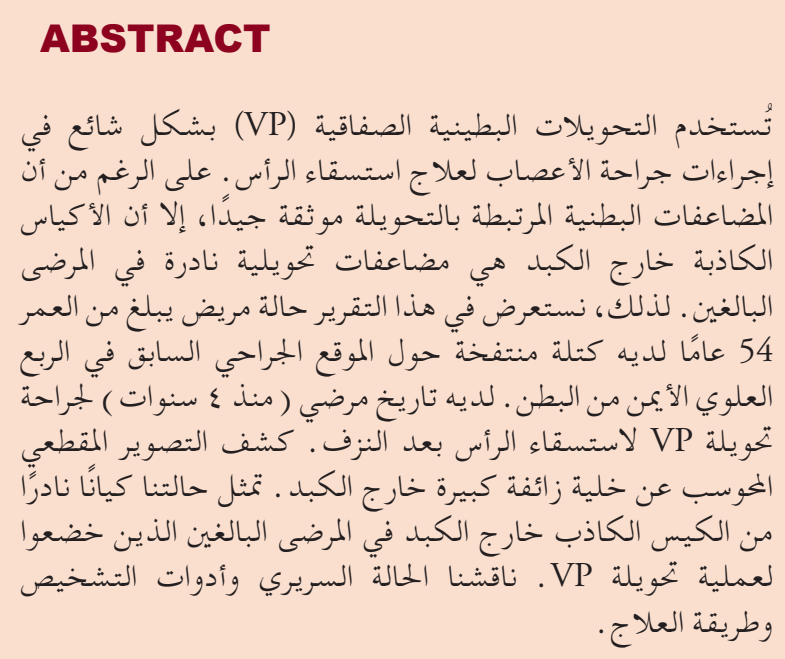

Ventriculoperitoneal (VP) shunts are commonly used in neurosurgical procedures to treat hydrocephalus. Although shunt-associated abdominal complications are well documented, extrahepatic pseudocysts are a rare shunt complication in adult patients. Therefore, we herein report the case of a 54-year-old male patient who presented with a bulging mass around the previous surgical site at the right upper quadrant of the abdomen. He had a 4-year history of VP shunt surgery for posthemorrhagic hydrocephalus. A computed tomographic scan revealed a large extrahepatic pseudocsyt. Our case represented a rare entity of extrahepatic pseudocyst in adult patients underwent VP shunt surgery. The clinical presentation, diagnostic tools, and treatment methods were discussed.

Neurosciences 2021; Vol. 26 (1): 97-102 doi: 10.17712/nsj.2021.1.20200117

From the Department of Neurological Surgery (Chen), Tri-Service General Hospital, National Defense Medical Center, from the Department of Medicine (Hsieh), School of Medicine, Fu Jen Catholic University, Taipei, from the Division of Neurosurgery (Hsieh), Department of Surgery, Sijhih Cathay General Hospital, from the Department of Medicine (Hsieh), School of Medicine, Fu Jen Catholic University, New Taipei, from the Section of Neurosurgery (Sun), Department of Surgery, Ditmanson Medical Foundation, Chia-Yi Christian Hospital, and the Department of Biotechnology (Sun), Asia University, Taichung, Taiwan.

Received 16th July 2020. Accepted 30th August 2020.

\begin{abstract}
Address correspondence and reprint request to: Dr. Jui-Ming Sun, Section of Neurosurgery, Department of Surgery, Ditmanson Medical Foundation, Chia-Yi Christian Hospital, Chiayi City, Taiwan. E-mail:07178@cych.org.tw

ORCID ID: https://orcid.org/0000-0002-4878-5084
\end{abstract}

$\mathrm{V}$ entriculoperitoneal (VP) shunts are commonly used in neurosurgical procedures to divert excess cerebrospinal fluid (CSF) from the ventricular system into the abdominal cavity, which is indicated for hydrocephalus related to congenital hydrocephalus, trauma, hemorrhage, neoplasms, infection, and various other conditions. ${ }^{1}$ Several abdominal complications are common in patients undergoing VP shunts, including pseudocysts, infection, and hollow organ perforation..$^{2,3}$ Catheter migrations may occur into the abdominal cavity including abdominal wall, small bowel, large bowel, gall bladder, liver, stomach, vagina, fallopian tube, urinary bladder, or scrotum. ${ }^{4-6}$ Abdominal pseudocysts occur in less than $10 \%$ of all patients receiving VP shunts and occur primarily in pediatric populations. ${ }^{7}$

Hepatic pseudocyst secondary to shunt operation is a rare entity, which is classified as intra-axial and extra-axial types. ${ }^{8}$ The intra-axial hepatic pseudocysts commonly demonstrate that the tip of the shunt can be dislodged into the liver parenchyma. ${ }^{9}$ By penetrating the Glisson's capsule, the distal tube cause subcapsular pseudocyst formation in patients with extra-axial hepatic pseudocysts. ${ }^{3}$ However, extrahepatic pseudocysts are rare shunt complications in adult patients, and only several cases have been reported in the relevant literature. ${ }^{10-15}$ Therefore, we herein report the development of extrahepatic pseudocysts following VP shunt surgery in a 54-year-old male patient. The clinical presentation, diagnostic tools, and treatment methods

Disclosure. The authors declare no conflicting interests, support or funding from any drug company. 
are also discussed to manage this rare complication.

Case Report. Patient information. This case report was approved by the Institutional Review Board of Chia-Yi Christian Hospital in Taiwan (No. IRB2020064). The timeline for this case report was summarized in Table 1. A 54-year-old male patient had a 4-year history of spontaneous intracerebral hemorrhage at the left basal ganglion with ventricular extension. Initially, the external ventricular device (EVD) was inserted. However, the intracranial pressures were persistently high and VP shunt surgery with medium pressure reservoir implantation (Medtronic, USA) was placed because of posthemorrhagic hydrocephalus. This VP shunt surgery was placed via open mini-laparatomy without a trocar and the peritoneal tube was placed freely in the peritoneum. Four years after the placement, he started to develop a progressive bulging mass around the previous surgical site at the right upper quadrant of the abdomen 2 weeks before admission.

Clinical findings. At admission, he was alert and orientated. His blood temperature was $36.3^{\circ} \mathrm{C}$. Physical examination revealed a soft, bulging mass around the previous surgical wound at the right upper quadrant of the abdominal wall, measuring approximately $3 \mathrm{~cm}$ $\times 3 \mathrm{~cm}$. There was no any redness around the distal shunt tube or pseudomeningocele around the valve. The reservoir function of the VP shunt was intact. Laboratory examination of peripheral blood revealed a white blood cell count of $5570 / \mu \mathrm{L}$ and a C-reactive protein level of $0.34 \mathrm{mg} / \mu \mathrm{L}$.

Diagnostic assessment. The computed tomographic (CT) scan of brain revealed brain atrophy, large encephalomalacia at left basal ganglion, and mild hydrocephalus (Figure 1). Abdominal radiography showed a loop of the peritoneal tube around the right upper quadrant of the abdomen (Figure 2). The subsequent CT scan of the abdomen indicated a small cyst-like lesion, measuring approximately $3.6 \mathrm{~cm} \times 2$ $\mathrm{cm} \times 3.5 \mathrm{~cm}$, which was found at the right anterior abdominal wall along the abdominal entry point of the shunt (Figure 3A). A large cystic lesion at the right extrahepatic region was also discovered, containing the peritoneal tube of the VP shunt (Figure 3B and C). The intraabdominal cystic lesion was found to measure approximately $16 \mathrm{~cm} \times 11 \mathrm{~cm} \times 16.5 \mathrm{~cm}$.

Therapeutic intervention. Because of the impression of the shunt-associated extrahepatic pseudocyst, the patient underwent distal externalization of the VP shunt and laparoscopic surgery to remove the cystic lesion. At operation, the laparoscopic view showed that a huge cystic lesion with a thin wall contained mildly turbid fluid and was approximately $16 \mathrm{~cm}$ in days after surgery. Finally, the distal shunt was ligated at the right anterior chest region. We removed the externalized distal end and leaved proximal end in place. The patient remained alert and orientated at the

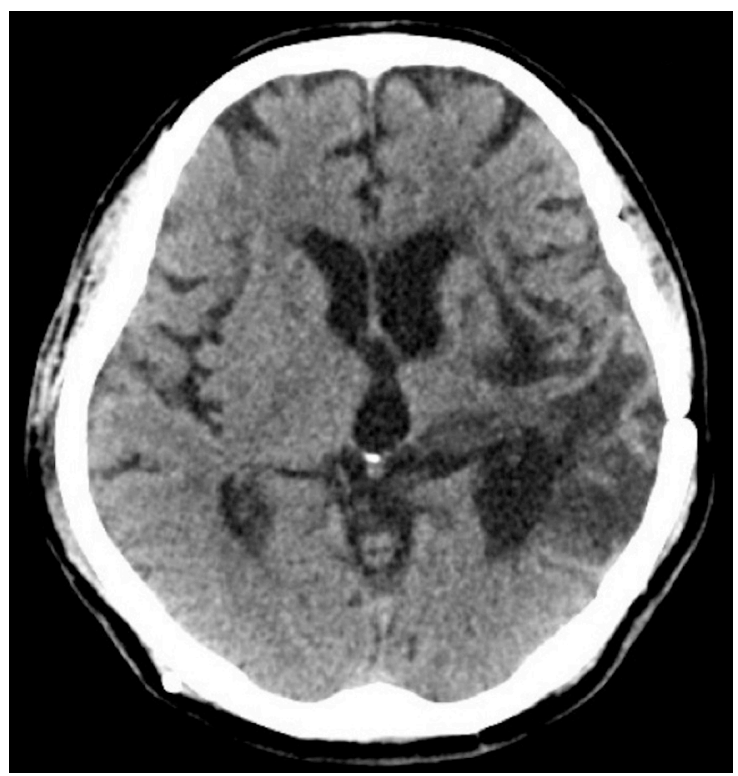

Figure 1 - Axial view of computed tomographic scan of brain revealed brain atrophy, large encephalomalacia at left basal ganglion, and mild hydrocephalus.

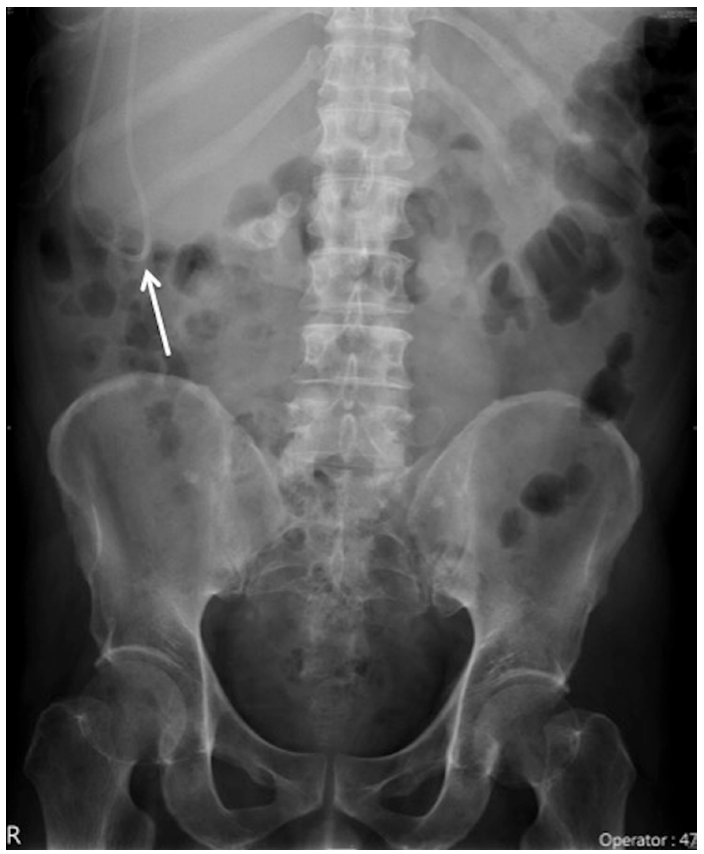

Figure 2 - Abdominal X-ray shows the peritoneal tip of the shunt in the right upper quadrant of the abdomen with a tube loop (white arrow). 
Table 1 - The timeline for the presented case.

\begin{tabular}{|c|c|c|c|}
\hline Date & \multicolumn{3}{|c|}{ Relevant Past Medical History and Interventions } \\
\hline & \multicolumn{3}{|c|}{$\begin{array}{l}\text { He had a 4-year history of spontaneous intracerebral hemorrhage at the left basal ganglion with ventricular extension and underwent VP } \\
\text { shunt surgery with medium pressure reservoir implantation (Medtronic, USA) because of posthemorrhagic hydrocephalus }\end{array}$} \\
\hline Date & $\begin{array}{l}\text { Summaries from Initial and Follow- } \\
\text { up Visits }\end{array}$ & Diagnostic Testing (including dates) & Interventions \\
\hline $2020 / 5 / 11$ & $\begin{array}{l}\text { A progressive bulging mass } \\
\text { around the previous surgical } \\
\text { site at the right upper } \\
\text { quadrant of the abdomen } 2 \\
\text { weeks before admission }\end{array}$ & $\begin{array}{l}\text { - Laboratory examination showed white blood cell } \\
\text { count of } 5570 / \mu \mathrm{L} \text { and a C-reactive protein level of } \\
0.34 \mathrm{mg} / \mu \mathrm{L} .(2020 / 5 / 11) \\
\text { Abdominal radiography showed a loop of the } \\
\text { peritoneal tube around the right upper quadrant } \\
\text { of the abdomen. }(2020 / 5 / 11) \\
\text { Computed tomography }(\mathrm{CT}) \text { scan of the } \\
\text { abdomen showed a large cystic lesion at the } \\
\text { right extrahepatic region was also discovered, } \\
\text { containing the peritoneal tube of the VP shunt. } \\
(2020 / 5 / 12) \\
\text { CSF culture: no bacterial growth }(2020 / 5 / 12 \text { to } \\
2020 / 5 / 14)\end{array}$ & $\begin{array}{l}\text { Distal externalization of the VP } \\
\text { shunt }(2020 / 5 / 12) \\
\text { - } \quad \text { Laparoscopic unroofing of the } \\
\text { cystic lesion }(2020 / 5 / 14) \\
\text { The distal shunt was ligated at } \\
\text { the right anterior chest region } \\
(2020 / 5 / 22) \\
\text { - Flomoxef } 1 \text { gm i.v. q8h }(2020 / 5 / 12 \\
\text { to } 2020 / 5 / 22)\end{array}$ \\
\hline $2020 / 5 / 23$ & $\begin{array}{l}\text { Discharge without symptoms of } \\
\text { hydrocephalus or fever }\end{array}$ & & \\
\hline $2020 / 7 / 28$ & $\begin{array}{c}\text { Alert and orientated. No recurrent } \\
\text { symptoms. }\end{array}$ & & \\
\hline
\end{tabular}

(A)

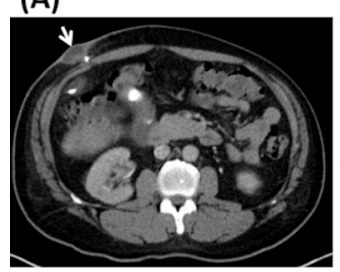

(B)

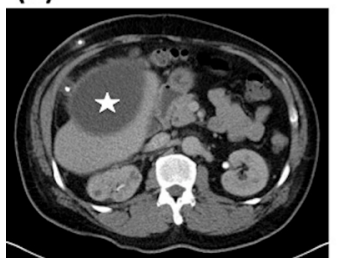

(C)

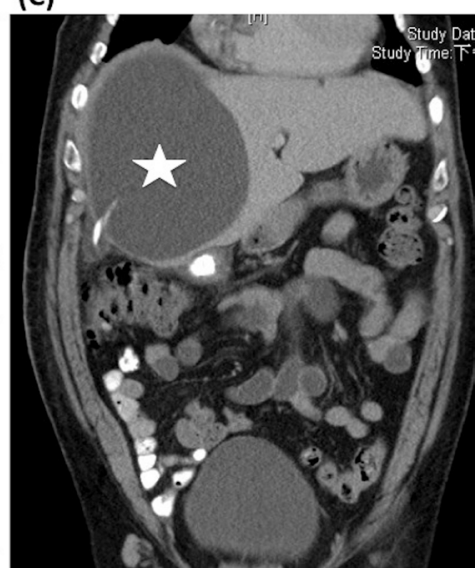

Figure 3 - Enhanced computed tomographic scan of the abdomen. (A) Axial view shows the subcutaneous cyst (white arrow) at the abdominal entry site of the shunt. (B) Axial view shows the peritoneal tube penetrating the extrahepatic pseudocyst (white asterisk). (C) Reconstructed coronal view shows the shunt tip (white arrow) penetrating the extrahepatic pseudocyst (white asterisk).

diameter. One fistula tract existed from the cystic wall to the abdominal wall. Surgical unroofing of the cystic lesion was performed (Figure 4). A microscopic view of this cystic lesion showed a dense thick fibrous wall and chronic granulomatous inflammation of histiocytes, lymphocytes, and plasma cells along the internal capsule (Figure 5). Outside the fibrous capsule, there was a small

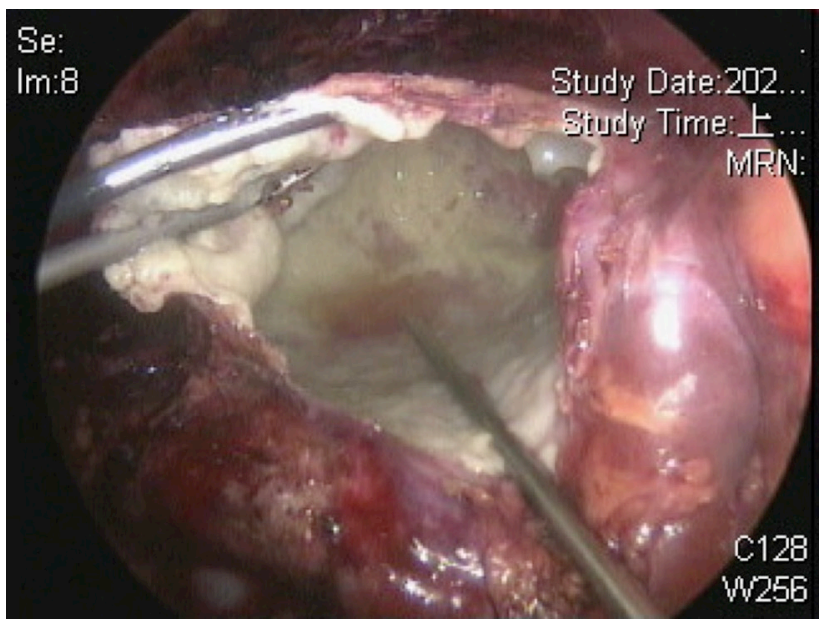

Figure 4 - Intraoperative laparoscopic view reveals the unroofing of the pseudocyst.

rim of atrophic liver tissue.Pathological examination confirmed the pseudocyst diagnosis.

Follow-up and outcomes. Postoperatively, the patient was afebrile. Flomoxef with a dose of $1 \mathrm{gm}$ every 8 hours was prescribed because of the externalized VP shunt. The total protein and glucose of CSF sampled from the externalized shunt were $31.2 \mathrm{mg} / \mu \mathrm{L}$ and $62 \mathrm{mg} / \mu \mathrm{L}$, respectively. The color of CSF was clear. No bacterial growth was found in a series of CSF cultures. A weaning trial from the VP shunt was successfully performed 7 


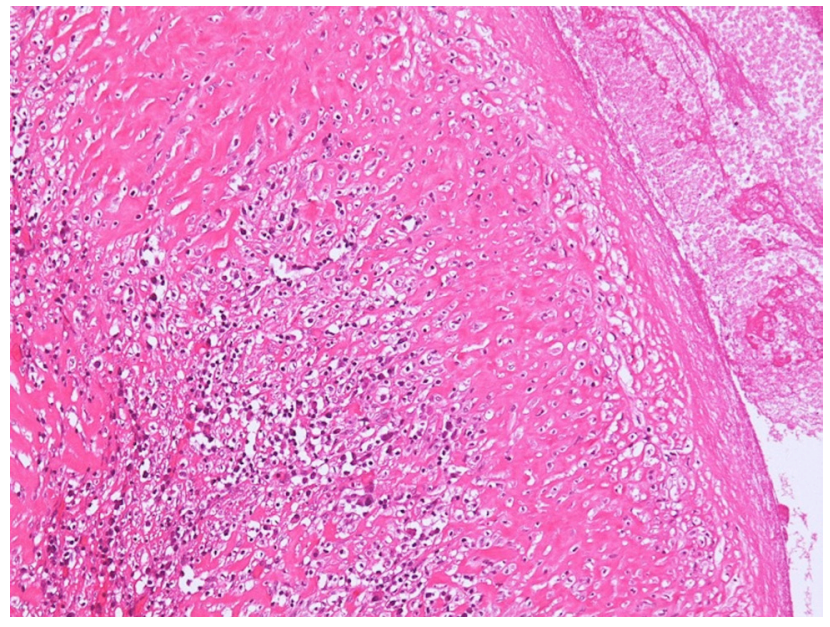

Figure 5 - The microscopic view of this cystic lesion demonstrates a dense thick fibrous wall and chronic granulomatous inflammation.

2-month follow-up. No abdominal discomforts were complained.

Discussion. Hydrocephalus is a common neurosurgical entity, and the peritoneal cavity is the most reliable and commonly used place for receipt of excess CSF from the ventricular system. ${ }^{1}$ Common VP shunt-associated abdominal complications include distal catheter migration, abscesses, peritonitis, CSF ascites, inguinal hernia, shunt malfunction caused by excessive intraperitoneal tube length, or pseudocysts. ${ }^{4,5}$ Abdominal pseudocysts, first reported by Harsh in $1954,{ }^{16}$ are a rare VP shunt-associated complication. The incidence of abdominal pseudocysts has been estimated to be approximately $0.25-10 \%$, and pediatric patients comprise the majority of cases. ${ }^{7,8}$ However, adult cases of shunt-associated extrahepatic pseudocysts have rarely been described, and only a few cases have been reported in the relevant literature. ${ }^{10-15}$

Although the etiology of abdominal pseudocysts remains unclear, the inflammatory process is the most likely cause. ${ }^{8,11}$ Several predisposing factors have been discovered, including (1) revision of shunt procedures, (2) peritoneal adhesion due to previous abdominal surgery, (3) malabsorption of CSF, (4) allergy to silicone or ethylene oxide, (5) an increase in the CSF protein content, or (6) intracranial tumors. ${ }^{7,8,17}$ Extra-axial type of hepatic pseudocysts may be caused by peritoneal tube's direct penetration or migration into Glisson's capsule, causing focal liver surface injury and further chronic irritation. ${ }^{11}$ In our case, the prior peritoneal shunt was placed through the use of the mini-open laparotomy method. No direct injury of Glisson's

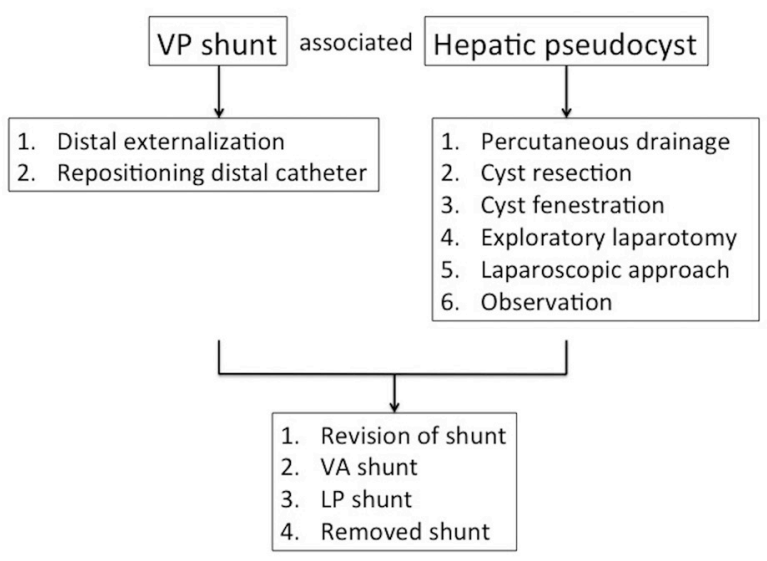

Figure 6 - The treatment algorithm for ventriculoperitoneal (VP) shunt-associated hepatic pseudocyst. For shunt, the distal externalization or repositioning distal catheter is initially suggested. For pseudocyst, the treatments include (1) percutaneous drainage, (2) cyst resection, (3) cyst fenestration, (4) exploratory laparotomy, (5) laparoscopic approach, or (6) observation. When the cerebral spinal fluid is sterile and hydrocephalus still exists, the revision of shunt, VA (ventriculoatrial) shunt, or lumboperitoneal (LP) shunt can be performed. Shunt may be removed when no hydrocephalus develops.

capsule was detected. No symptoms were noted for more than 4 years, and all CSF cultures were sterile during this admission. Otherwise, the histological features of the cystic lesion in our case demonstrated the invasion of lymphocytes, indicating an inflammatory reaction. ${ }^{17}$ Therefore, focal inflammation secondary to the migration of the peritoneal tube into Glisson's capsule may have contributed to the formation of extrahepatic pseudocysts in our patient.

Although the typical presentation of hepatic pseudocysts is poorly defined, several symptoms such as abdominal pain, abdominal distention, local tenderness around the abdominal entry site of the shunt, or abdominal masses should be considered as indicators of pseudocysts. ${ }^{18}$ Neurological complaints related to hepatic pseudocysts may be infrequent because the CSF absorption initially decreases, but the dose not cease entirely. ${ }^{8}$ Otherwise, a $17 \%-80 \%$ infection rate has been reported for abdominal pseudocysts, and Staphylococcus aureus and S. epidermidis are the most commonly detected bacteria. ${ }^{19}$ However, the infection incidence is lower in adults (15\%) than in children (33\%). ${ }^{7}$ Furthermore, smaller abdominal pseudocysts tend to be infected, and larger pseudocysts tend to be sterile. ${ }^{2}$ Although CSF studied in the reported cases of extrahepatic pseudocysts in adults has been 
mostly sterile, ${ }^{10,12-14}$ CSF culture should nonetheless be performed for the prevention of severe intraabdominal infection before revision of the shunt.

Mesenteric cysts, omental cysts, duplication cysts, lymphoceles, cystic teratomas, cystic lymphangiomas, pancreatic pseudocysts, abscesses, and bilomas should be included for the various diagnoses of abdominal pseudocysts. ${ }^{14}$ Ultrasonography has been introduced for easy diagnosis of pseudocsyts, which typically demonstrate a well-defined sonolucent mass with posterior acoustic enhancement. ${ }^{2}$ The shunt tip within the pseudocyst can also be identified. However, CT scans are considered to be more reliable and valuable for investigating abdominal pseudocysts. Most extrahepatic pseudocysts are characterized as parenchyma-free capsule formations with smooth margins extending outward from the liver and isodense cyst content with CSF. Nuclear medicine can also be used to evaluate shunt patency. ${ }^{20}$ The loculation of a radioactive tracer within the abdominal collection suggests pseudocyst formation after the injection of radioisotopes into the shunt reservoir. ${ }^{2}$

Some treatment algorithms have been described for the management of abdominal pseudocysts. ${ }^{21,22}$ The shunt tap is the most vital step in the confirmation of further treatment requirements. If infection is initially eliminated, distal catheter repositioning is the only suitable method for the treatment of patients with sterile abdominal pseudocysts. ${ }^{4}$ If infection is suspected or the status is unknown, distal tube externalization followed by appropriate antibiotic treatment is recommended. ${ }^{8,21}$ Furthermore, laparotomy with adhesion lysis, abdominal pseudocyst aspiration, or shunt removal can potentially be performed depending on the complexity of shuntassociated intraabdominal complications. If the CSF is sterile, the peritoneal cavity, pleural space, atrium, or gallbladder can be used to reposition the distal catheter for patients who remain shunt-dependent. ${ }^{22}$ Reaccumulation of pseudocysts remains a challenge for pediatric patients with abdominal pseudocysts who have undergone fluid drainage followed by the externalization or revision of shunts. ${ }^{1}$ In a literature review of adult cases with hepatic pseudocysts, Dabdoub et al observed no recurrences after the revision of the shunt, even in cases of infection. ${ }^{8}$ Our patient presented with a typical large hepatic pseudocyst containing sterile CSF. However, our patient required no further revision of the shunt following distal tube externalization after the successful weaning test. Based on the reported cases with hepatic pseudocysts, the treatment algorithm is simply summarized in Figure 6.

In conclusion, adult extrahepatic pseudocysts are a rare shunt complication. Abdominal pseudocysts should be considered in VP shunt patients with abdominal complaints. Early diagnosis and surgical intervention are the keystones to the management of this rare complication.

\section{References}

1. Dzongowski E, Coriolano K, de Ribaupierre S, Jones SA. Treatment of abdominal pseudocysts and associated ventricuoperitoneal shunt failure. Childs Nerv Syst 2017; 33: 2087-2093.

2. Pathi R, Sage M, Slavotinek J, Hanieh A. Abdominal cerebrospinal fluid pseudocyst. Australas Radiol 2004; 48: 61-63.

3. Arsanious D, Sribnick E. Intrahepatic Cerebrospinal Fluid Pseudocyst: A Case Report and Systematic Review. World Neurosurg 2019; 125: 111-116.

4. Popa F, Grigorean VT, Onose G, Popescu M, Strambu V, Sandu AM. Laparoscopic treatment of abdominal complications following ventriculoperitoneal shunt. J Med Life 2009; 2: 426-436.

5. Naftel RP, Argo JL, Shannon CN, Taylor TH, Tubbs RS, Clements RH, et al. Laparoscopic versus open insertion of the peritoneal catheter in ventriculoperitoneal shunt placement: review of 810 consecutive cases. J Neurosurg 2011; 115: 151-158.

6. Ezzat AAM, Soliman MAR, Hasanain AA, Thabit MA, Elshitany H, Kandel H, et al. Migration of the Distal Catheter of Ventriculoperitoneal Shunts in Pediatric Age Group: Case Series. World Neurosurg 2018; 119: e131-e137.

7. Dabdoub CB, Dabdoub CF, Chavez M, Villarroel J, Ferrufino JL, Coimbra A, et al. Abdominal cerebrospinal fluid pseudocyst: a comparative analysis between children and adults. Childs Nerv Syst 2014; 30: 579-589.

8. Dabdoub CB, Fontoura EA, Santos EA, Romero PC, Diniz CA. Hepatic cerebrospinal fluid pseudocyst: A rare complication of ventriculoperitoneal shunt. Surg Neurol Int 2013; 4: 162.

9. Kaplan M, Ozel SK, Akgun B, Kazez A, Kaplan S. Hepatic pseudocyst as a result of ventriculoperitoneal shunts: case report and review of the literature. Pediatr Neurosurg 2007; 43: 501-503.

10. Faraj W, Ahmad HH, Mukherji D, Khalife M. Hepatic cerebrospinal fluid pseudocyst mimicking hydatid liver disease: a case report. J Med Case Rep 2011; 5: 475.

11. Hsieh CT, Pai CC, Tsai TH, Chiang YH, Su YH. Hepatic cerebrospinal fluid pseudocyst: a case report and review of the literature. Neurol India 2006; 54: 86-88.

12. Peltier J, Demuynck F, Fichten A, Lefranc M, Toussaint P, Desenclos C, et al. Non-traumatic pseudocyst of Glisson capsule complicating a ventriculoperitoneal shunt. Neurochirurgie 2011; 57: 31-33.

13. Wolbers JG, van Zanten TE, van Alphen HA. Ventriculoperitoneal shunt procedure complicated by liver capsule perforation. A case report. Clin Neurol Neurosurg 1987; 89: 55-57.

14. Canaz G, Emel E, Baydin S, Ulukent SC, Ozgunduz Y, Cevik OM. Safe surgical approach to extrahepatic pseudocyst, a rare shunt complication: 2 case reports. Chinese Neurosurgical Journal 2017; 3: 36. 
15. Verma A, Mohan S, Gupta A. Ventriculo-peritoneal shunts can cause liver injury, juxta and intrahepatic pseudocysts: imaging findings and review of literature. Clin Neurol Neurosurg 2012; 114: 389-391.

16. Harsh GR, 3rd. Peritoneal shunt for hydrocephalus, utilizing the fimbria of the fallopian tube for entrance to the peritoneal cavity. J Neurosurg 1954; 11: 284-294.

17. Ohba S, Kinoshita Y, Tsutsui M, Nakagawa T, Shimizu K, Takahashi T, et al. Formation of abdominal cerebrospinal fluid pseudocyst. Neurol Med Chir (Tokyo) 2012; 52: 838-842.

18. Bettis T, Holsten S, Mitchell A. Conservative Management of a Hepatic CSF Pseudocyst in an Asymptomatic Patient. Am Surg 2019; 85: e389-e391.
19. Hamid R, Baba AA, Bhat NA, Mufti G, Mir YA, Sajad W. Post ventriculoperitoneal shunt abdominal pseudocyst: Challenges posed in management. Asian J Neurosurg 2017; 12: 13-16.

20. Vettiyil B, Bessette S, McQuiston S, Greiner F. Nuclear Medicine to Evaluate Complications of Cerebral Shunts: Two Cases and Review of Literature. World J Nucl Med 2015; 14 : 212-215.

21. Mobley LW, 3rd, Doran SE, Hellbusch LC. Abdominal pseudocyst: predisposing factors and treatment algorithm. Pediatr Neurosurg 2005; 41: 77-83.

22. Erwood A, Rindler RS, Motiwala M, Ajmera S, Vaughn B, Klimo P, et al. Management of sterile abdominal pseudocysts related to ventriculoperitoneal shunts. J Neurosurg Pediatr 2019; $7: 1-5$.

\section{Supplements}

* Supplements will be considered for work including proceedings of conferences or subject matter covering an important topic

* Material can be in the form of original work or abstracts.

* Material in supplements will be for the purpose of teaching rather than research.

* The Guest Editor will ensure that the financial cost of production of the supplement is covered.

* Supplements will be distributed with the regular issue of the journal but further copies can be ordered upon request.

* Material will be made available on Saudi Medical Journal website 